\title{
Expansão urbana de Macapá, no Amapá: o caso da zona norte
}

\author{
Urban Expansion of Macapá, in Amapá: The case of the North Zone
}

\section{Taís Oliveira de Morais ${ }^{1}$ \\ Ananda Brito Bastos ${ }^{2}$ \\ Robson Matheus de Araújo Silva ${ }^{3}$ \\ Daguinete Maria Chaves Brito 4}

\begin{abstract}
1 Bacharel em Arquitetura e Urbanismo. Universidade Federal do Amapá. E-mail: taisoliveira.96.to@gmail.com 2 Acadêmica em Arquitetura e Urbanismo. Universidade Federal do Amapá. E-mail: nanda.nanb.b@gmail.com 3 Acadêmico em Engenharia Florestal. Universidade do Estado do Amapá. E-mail: robson.eflueap@gmail.com 4 Doutora e Docente do Curso de Geografia, Universidade Federal do Amapá. E-mail: dagnete@uol.com.br
\end{abstract}

RESUMO: Este artigo objetiva analisar a expansão urbana de Macapá, Estado do Amapá, com destaque para a Zona Norte da cidade. Metodologicamente, utilizou-se a pesquisa bibliográfica e observações in loco para comparar a teoria a realidade local. Os resultados permitiram traçar uma análise da definição das tipologias de bairros, as diversas formas de ocupação territorial que vem ocorrendo na área, as consequências da falta de planejamento urbano na cidade, a falta de equipamentos urbanos e a degradação social e ambiental, além de traçar um perfil histórico-geográfico para a área, além de delinear um prognóstico da área de estudo.

Palavras-chaves: Expansão urbana. Apropriação territorial. Bairro. Loteamento. Macapá.

ABSTRACT: This article aims to analyze the urban expansion of Macapá, State of Amapá, with emphasis on the North Zone of the city. Methodologically, bibliographical research and on-site observations were used to compare theory to local reality. The results allowed for an analysis of the definition of neighborhood typologies, the different forms of territorial occupation that are occurring in the area, the consequences of the lack of urban planning in the city, the lack of urban equipment and social and environmental degradation, as well as a geographical-historical profile for the area, in addition to delineating a prognosis of the study area.

Keywords: Urban expansion. Territorial appropriation. Neighborhood. Allotment. Macapá.

Sumário: Introdução - 1 Formas de Ocupação do Território da Zona Norte de Macapá - 2 Consequências da Expansão na Zona Norte - Considerações Finais - Referências

\section{INTRODUÇÃO}

As cidades no século XXI sofrem grandes transformações sociais e territoriais e cada vez mais o crescimento populacional vem gerando diferentes formas de ocupação e apropriação do território urbano, esse crescimento é causado pela falta de políticas públicas adequadas e tem como consequências a segregação urbana e desigualdade social, ocorrendo cobranças ao poder público, aos planejadores e aos gestores urbanos soluções que tornem as cidades em espaços sustentáveis e adequados, tendo como consequências a melhoria da qualidade de vida para a sociedade.

Na cidade de Macapá, capital do estado do Amapá, estas transformações não são diferentes, de acordo com o Instituto Brasileiro de Geografia e Estatística - IBGE (2010a) a população do Município de 
Macapá está concentrada na cidade, estima-se que a população macapaense em 2018 era de 493.634 pessoas, mais de $90 \%$ da população reside na área urbana, gerando problemas sociais, urbanos e ambientais dento da cidade.

Como uma das consequências tem-se a expansão urbana ocorrida em direção à Zona Norte da cidade, que se deu pelo crescimento desenfreado da população, levando a ocupação daquela região, pois as áreas de expansão planejada para a cidade seriam insuficientes para o quantitativo de pessoas que estavam ocupando a área.

Esta expansão ocorreu dentro da zona norte com formas distintas, a partir da criação de loteamentos, assentamentos irregulares e de conjuntos habitações de interesses sociais. Para a compreensão desta pesquisa serão analisados os conceitos e mencionados exemplos práticos de cada tipologia de ocupação do território urbano na área norte da cidade.

De acordo com o Plano Diretor de Macapá (PMM, 2004), a Zona Norte da cidade compreende os bairros e loteamentos: Pantanal, Renascer I e II, Infraero I e II, São Lázaro, Novo Horizonte, Jardim Felicidade I e II, Sol Nascente, Alencar, Boné Azul, Liberdade e Brasil Novo e as demais áreas contidas no limite norte da cidade, como Açaí, Parque dos Buritis, Ilha Mirim, loteamento Ipê e Morada das Palmeiras, além de outros loteamentos em estruturação.

Neste sentido, o presente artigo tem como objetivo apresentar essas tipologias de apropriação do território que constituíram e deram forma para reestrutura da Zona Norte de Macapá. E após apresentação de conceitos e exemplos dos tipos de apropriação do espaço urbano, o estudo pretende analisar quais conflitos urbanos existem na região, assim como refletir sobre os impactos e as expectativas para o norte da área urbana de Macapá, tendo como metodologia a utilização de arcabouço teórico com a utilização de autores clássicos e locais e da pesquisa in loco (visitas direcionadas na Zona Norte de Macapá).

\section{FORMAS DE OCUPAÇÃO DO TERRITÓRIO DA ZONA NORTE DE MACAPÁ}

$\mathrm{Na}$ literatura nacional e internacional há descrição de várias formas de ocupação da territorialidade urbana. Entretanto, uma das principais formas é a constituição de bairros. Para Bezerra (2012, p.22) "a discussão acerca do entendimento do conceito de bairro é vasta e, por conseguinte, bastante instigante". Dentre as interpretações que o autor apresenta, destaca-se duas formas de definir o termo bairro: a definição administrativa e a definição subjetiva, a esse respeito o teórico afirma que

Percebemos que os limites administrativos devem coexistir assim como os limites subjetivos, pois, na maioria das vezes, eles não coincidem. Entendemos que a divisão administrativa faz-se necessária porque é a partir destes limites que aquele recorte é identificado oficialmente e planejado ou assistido pelo órgão gestor; e os limites subjetivos fazem-se necessários porque, a partir da coletividade, é que as reivindicações tomam corpo e o suporte físico o faz único (BEZERRA, 2012, p.27).

Assim, é possível observar que existe conflitos relacionados as definições de bairros, com relação a teoria e a realidade. Esta constatação pode ser percebida quando se analisa os critérios de pesquisas utilizados pelo IBGE, pois este Instituto considera apena o conceito administrativo de bairro teorizado por Bezerra (2012). Ou seja, a pesquisa realizada pelo IBGE no Censo de 2010 considerou apenas os bairros oficiais, aqueles criados pelo poder público municipal, que foram: Boné Azul, Brasil Novo, Infraero, Jardim Felicidade, Novo Horizonte e São Lázaro (IBGE, 2010a).

Porém, existem muitas outras áreas que apesar de administrativamente serem citadas como 
loteamentos, no senso comum essas áreas já são consideradas bairros, como exposto na figura 1, apresentando o conceito subjetivo de bairro explicado por Bezerra (2012). Como é o caso do Loteamento Liberdade e o Brasil Novo, os quais segundo Cantuária (2011) foram unificados por lei e denominados apenas de Brasil Novo.

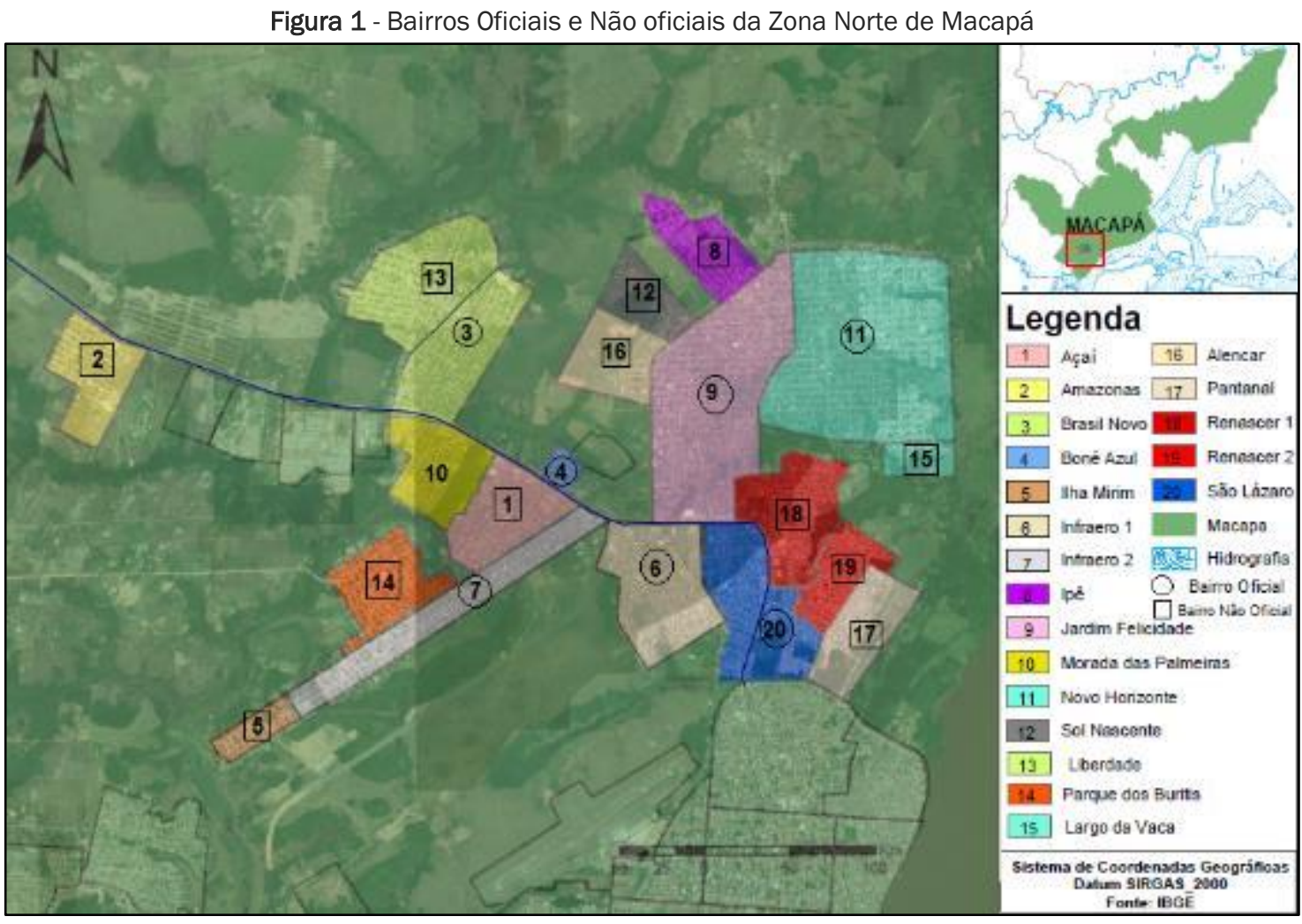

Fonte: Adaptado Google Earth (2018).

Para Cantuária (2011, p.91) “a divisão do IBGE deve-se ao fato de loteamentos como Pantanal, Ipê e Renascer ainda não terem leis específicas estabelecendo seus limites”. Essa é uma condição de invisibilidade dos bairros e tem como principal consequência as dificuldades de condições mínimas de habitações nestas áreas. Para Toste (2016a) a falta de regulamentação provoca grandes limitações fundiárias para a população que reside nestes lugares, sobretudo, quando tentam obter financiamento públicos.

Portanto, deve-se compreender o bairro não apenas com uma a unidade territorial delimitada para a avaliação dos processos da vida urbana. Mas também, por meio das semelhanças morfológicas, assim, como da vivência e do agir social, consolidado a partir da sua história. Segundo observações in loco, verificou-se que, de modo geral, não existem uma delimitação física visível na maioria dos bairros da Zona Norte da área urbana de Macapá, o que causa dificuldades de definição quanto aos limites dos bairros existentes, os quais podem ser formados por bairros oficiais, loteamentos, aglomerados subnormais e conjuntos habitacionais (figura 2). 
Figura 2 - Delimitações dos bairros da Zona Norte de Macapá.

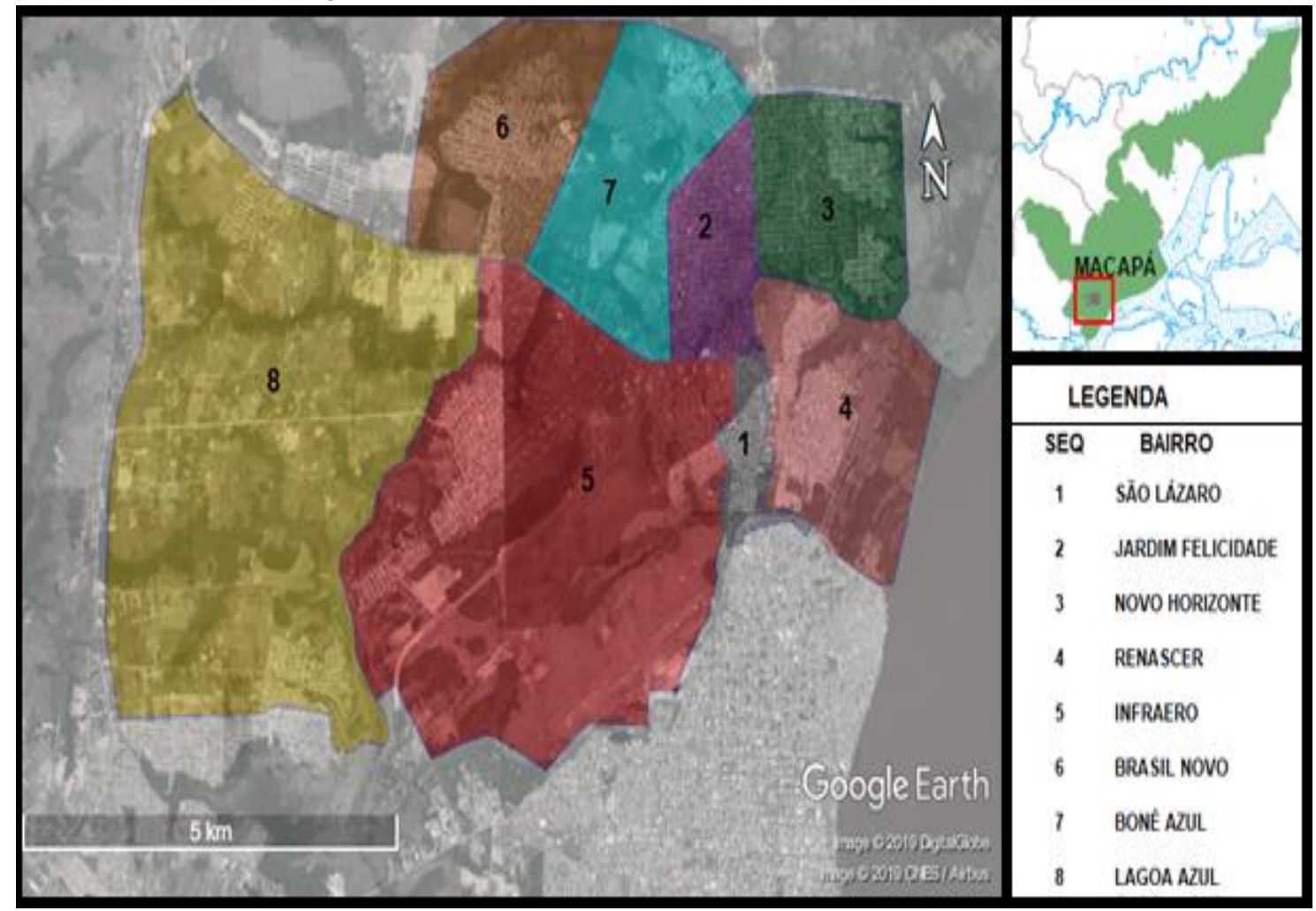

Fonte: Fonte: Adaptado Google Earth (2018).

Segundo Tostes (2016a), até a década de 1980 a Zona Norte da cidade de Macapá compreendia apenas os bairros do Laguinho, Perpétuo Socorro e Jesus de Nazaré. A expansão continuou no sentido norte em direção ao atual Canal do Jandiá, originando o bairro do Pacoval. Do outo lado do Canal existia até então, a Lixeira Pública de Macapá, instalada no Km 0 da BR-156, o qual em meados de 1977, já possuía nas proximidades um aglomerado de barracos de invasão (MARINHO, 1997).

Marinho (1997) afirma, ainda, que essas ocupações irregulares iniciais deram origem ao bairro São Lázaro, cujo primeiros moradores eram provenientes das regiões rurais do município de Macapá. Para Cantuária (2011) seguindo essa tendência, outras áreas periféricas, também, foram gradualmente ocupadas entre as décadas de 1980 e 1990, tais como o do Loteamento Jardim Felicidade (1985) e Novo Horizonte (1994), dentre outros.

Neste sentido, a formação inicial da Zona Norte da área urbana de Macapá é um exemplo real e reforça o argumento de Cardoso (2016, p.29) sobre as dificuldades de acesso à terra e à moradia, a qual "só se viabilizou por meio de processos de ocupação de terras ociosas e da autoconstrução da moradia, gerando assentamentos insalubres, frequentemente ocupando áreas de risco”.

De acordo com o IBGE (2010b) os assentamentos irregulares são classificados como aglomerados subnormais, caracterizados principalmente pela ocupação ilegal de terra e precariedade de serviços públicos essenciais. Assim, observando estes critérios, as invasões, representados por loteamentos irregulares ou clandestinos e áreas invadidas são considerados aglomerados subnormais.

Considerando estes critérios na Zona Norte da área urbana de Macapá existem aglomerados subnormais, incluindo nesta situação as áreas não edificantes, como as áreas de ressaca e os Loteamentos Liberdade, Largo da Vaca e Canal do Jandiá, localizadas nos bairros do Brasil Novo, Novo Horizonte e 
fronteira do São Lázaro com o Pacoval, respectivamente.

Mas além desses, como consta no documento "Histórico de Loteamentos Urbanos" do Instituto de Meio Ambiente e Ordenamento Territorial do Amapá - IMAP (s.d.), também, existem os loteamentos Palmares e Esperança do Renascer, que foram criados pelo poder público, porém, foram ocupados de forma ilegal.

Com base em informações colhidas no site do IMAP (s.d.) é necessário esclarecer que no caso dos loteamentos, somente são classificados como irregulares ou clandestinos, quando não há a aprovação do projeto de ocupação da área pela prefeitura do município. Quanto a definição do termo loteamento "é a divisão de uma grande área de terra em lotes menores destinados à edificação” (IMAP, s.d.). O Instituto afirma, ainda, que o loteador responsável pode ser tanto uma pessoa física, como entidade pública ou privada.

Para Matsutane et. al. (2017) os loteamentos fundados com a anuência do poder público têm por objetivo o assentamento de famílias de média e baixa renda, como modo de solucionar problemas socioeconômicos e urbanos encontrados pela urbanização desordenada dentro das cidades e por isso são caracterizados como loteamentos populares ou de interesse social.

Portilho (2006), afirma que ao longo da década de 1990, Macapá presenciou a implementação de diversos loteamentos caracterizados como populares ou de interesse social, sobretudo, na região norte da cidade. Com base nos dados do documento "Histórico de Loteamentos Urbanos" do IMAP (s.d.) e em Cantuária (2011) é possível afirmar que os loteamentos de interesse social da Zona Norte instituídos na década de 1990 foram: o Brasil Novo (1990), Infraero (1997), Renascer (1998), Pantanal (1998), Liberdade (1999) e Amazonas (2000).

Ainda de acordo com Portilho (2006, p.118) "a implantação de loteamentos populares foi sendo imposta em locais cada vez mais distantes do centro urbano". O que para a autora causou custos mais altos para implementação de infraestrutura urbana, serviços urbanos coletivos, além de contribuir para a segregação do espaço urbano de Macapá.

Em contraponto aos loteamentos populares, existe os loteamentos criados pela iniciativa privada. Para Rodrigues (2008) os loteamentos privados ou fechados podem ser definidos como os loteamentos convencionais, regidos pela Lei federal n 6.766, de 1979 e são fechados por ato do loteador ou por uma associação de moradores.

Porém, de acordo com Amaral e Melo (2013, p. 26) o fato de os loteamentos privados serem fechados, constitui certa ilegalidade pois "o que se comercializa são apenas lotes, como em qualquer outro loteamento ou bairro da cidade”. Argumento reforçado por Rodrigues (2016, p.153 apud SILVA, 2017, p.435) ao comentar que os loteamentos fechados "são irregulares porque não seguem a legislação condominial, regida no Brasil pela Lei Federal n 4.591, de 1964, e que, muitas vezes, esses empreendimentos são chamados de condomínios, com objetivo de burlar a vigilância”.

Segundo Rodrigues (2008) essa nova maneira de ocupação ocorre principalmente em regiões consideradas periféricas, devido essas áreas possuírem maior extensão territorial, terras com menor valor de mercado e estarem localizadas em regiões de fácil acesso, o que de acordo com Amaral e Melo (2013), também, ocorre em Macapá.

Amaral e Melo (2013) e Silva (2017) explicam que no contexto da Zona Norte de Macapá, os loteamentos privados surgem a partir dos anos 2000 e se intensificam a partir da década de 2010. Com base em Rodrigues (2008, p.4) esse crescimento ocorre devido os loteamentos privados serem "a resposta espacial 
encontrada que mais se repete no crescimento das cidades brasileiras”, pois é comercializada para a população de classe média e alta e é disseminada a ideia de maior qualidade de vida e segurança.

A partir das pesquisas de Silva (2017), bem como nas observações in loco, constata que que atualmente existem dezesseis loteamentos privados em toda a cidade de Macapá, sendo seis localizados na Zona Norte, os quais são: o loteamento Jardim Caranã, Bella Vista, Floresta Tropical, Amazon Ville, Terra Nova I e II (figura 3).

Figura 3 - Localização dos loteamentos privados da Zona Norte de Macapá

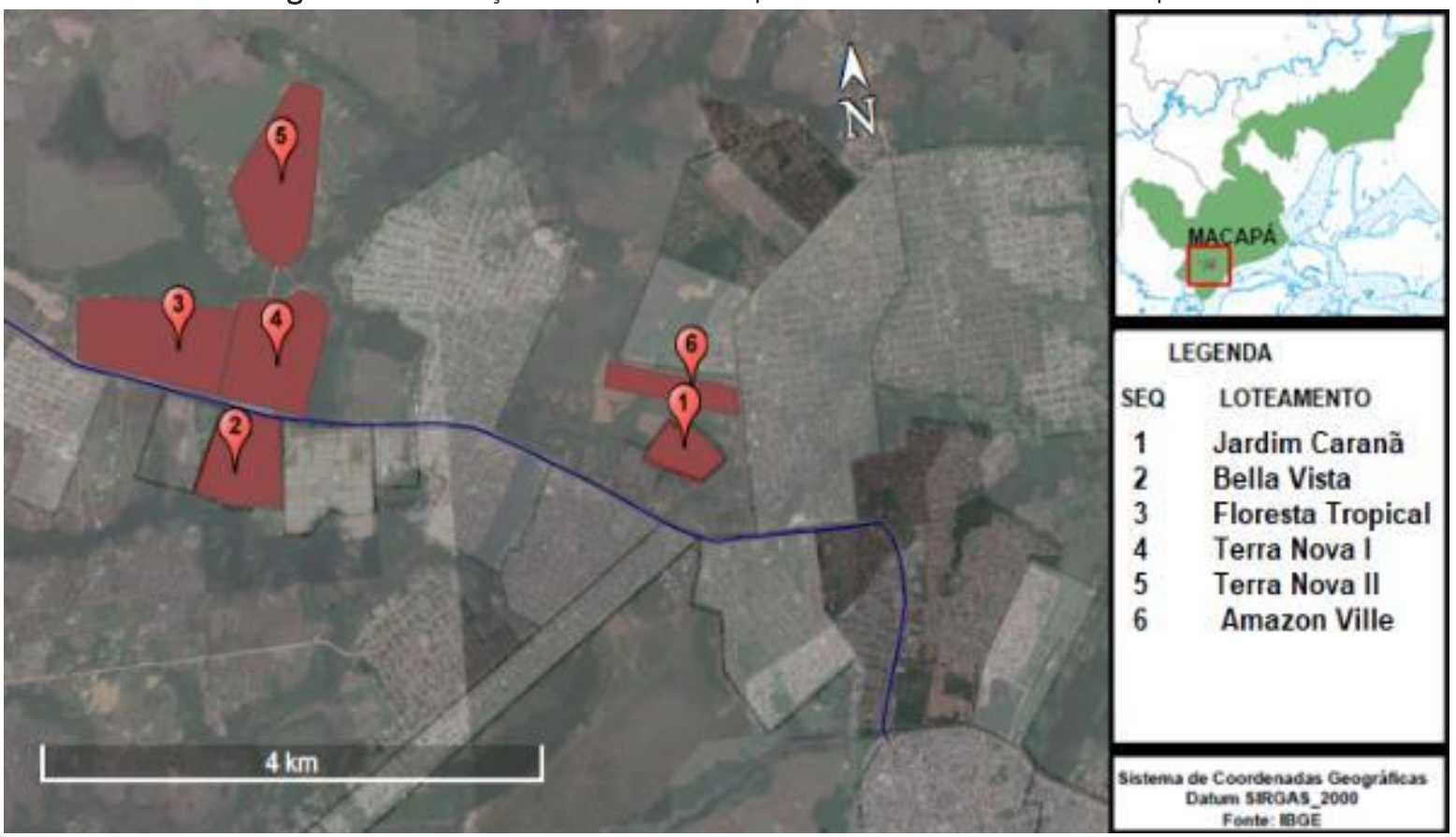

Fonte: Adaptado Google Earth (2018).

Assim, os loteamentos privados são parte da "reestruturação urbana que tem atingido as cidades médias brasileiras” (AMARAL; MELO, 2013, p.26) provocado principalmente pelo setor imobiliário, o qual por meio de incorporadoras e construtoras atuam "como agentes importantes na promoção da expansão urbana e na produção da cidade" (SILVA, 2017, p.433-434).

Silva (2017) comenta que no mesmo período em que o setor privado começa a atuar mais ativamente na produção do espaço urbano de Macapá, ocorre uma "mudança no papel do estado no que se refere à condução do processo de expansão urbana". A mudança citada pela autora é a decisão do poder público de priorizar a edificação de conjuntos habitacionais, os quais se diferenciam dos loteamentos populares, por fornecer a construção de moradias para a população de baixa renda.

Segundo Tostes (2016b), o conjunto do Boné Azul pode ser considerado o primeiro projeto habitacional criados pelo estado para a Zona Norte de Macapá. O conjunto surgiu no final do ano de 1990, por meio de linha de financiamento da Caixa Econômica Federal (CEF). Porém, como argumentado por Martinez et. al. (2013) os programas habitacionais criados pelos governos municipais e estaduais após a década de 1980, não conseguiram reduzir significativamente o déficit habitacional.

Como forma de diminuir a problemática habitacional, bem como retirar a população mais carente de aglomerados subnormais, em 2009, foi instituído pelo governo federal o programa "Minha Casa, Minha Vida", que incluiu todas as regiões do país, inclusive o estado do Amapá (SILVA, 2017). Os conjuntos 
habitacionais de interesse social, que são parte desse programa federal, começaram a ser edificados em Macapá a partir de 2010, e hoje existem dois na região norte da cidade: o Conjunto Mestre Oscar Santos e o Macapaba (figura 4).

Figura 4 - Localização dos loteamentos privados da Zona Norte de Macapá

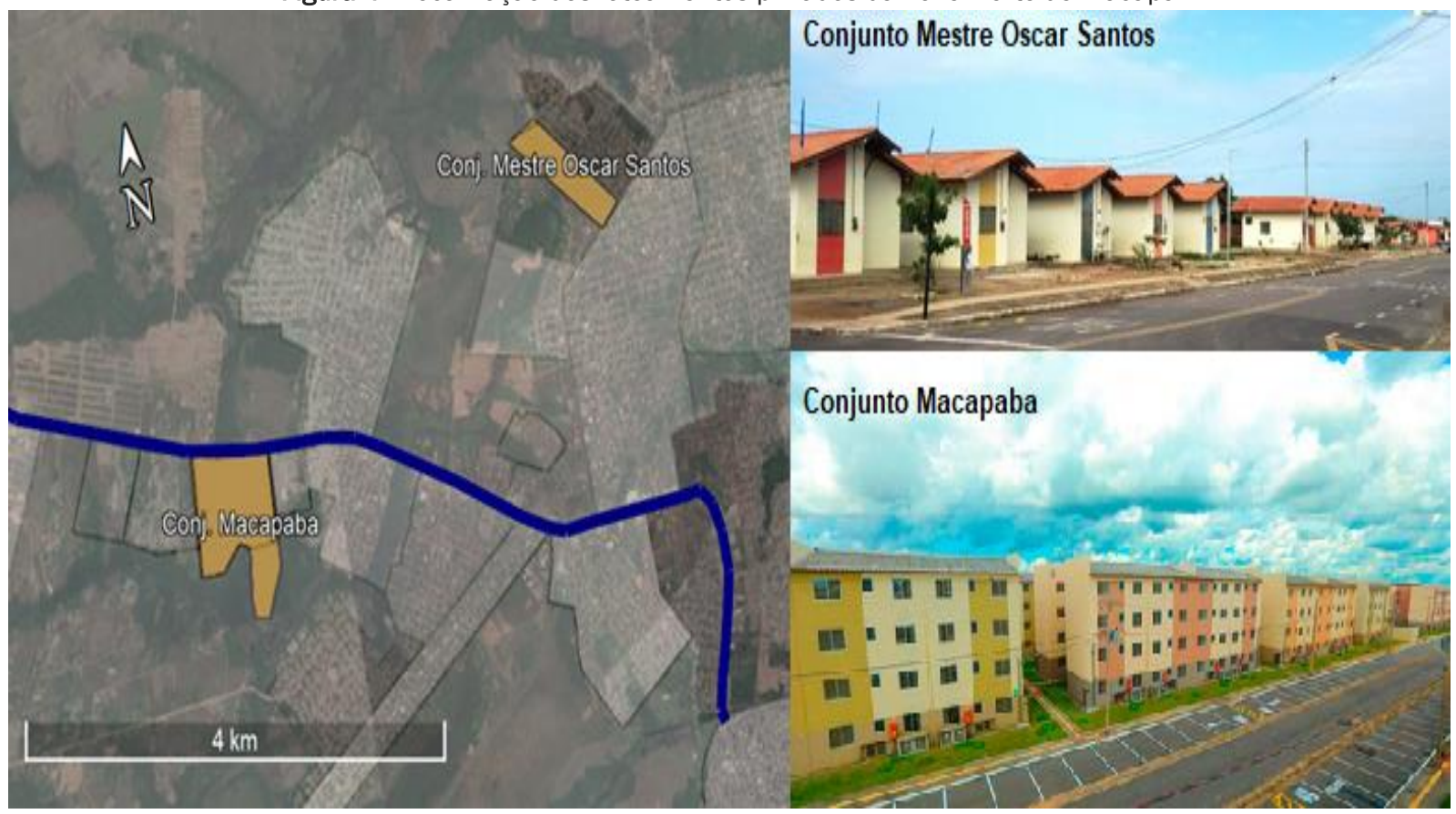

Fonte: Adaptado Google Earth; Seles Nafes.com; Arquivo/Secom (2018).

Conforme comentado por Silva (2017, p. 434) a maior parte dos conjuntos habitacionais erguidos em Macapá foram construídos em áreas que já possuem algum tipo de infraestrutura, com exceção do Conjunto Macapaba, pois foi "construído em uma área de expansão urbana, pouco ocupada, e o Estado teve de colocar a infraestrutura básica”. Tostes (2016b) critica essa ausência de integração entre área do Macapaba e o seu espaço urbano, além do descumprimento de legislações urbanísticas para a construção do conjunto.

\section{CONSEQUÊNCIAS DA EXPANSÃO NA ZONA NORTE}

São vários os reflexos, tanto positivo como negativos, da urbana de determinada cidade e segundo Palheta et. al. (2016) a expansão não planejada ocorrida na Zona Norte de Macapá trouxe consequências negativas para cidade tanto no âmbito social quanto ambiental. Palheta et. al. (2016) e Carvalho (2013) citam algumas dessas consequências como: a segregação socioespacial, falta de investimento público, desvalorização da terra, degradação de áreas verdes e diminuição da qualidade urbana ambiental das cidades.

$\mathrm{Na}$ área de estudo observou-se a segregação socioespacial. Este fenômeno ocorre a partir de dois aspectos, o primeiro entre a Zona Norte e o restante da área urbana de Macapá, e o segundo entre o espaço urbano da Zona Norte e os novos empreendimentos de loteamentos fechados.

Conforme Viégas (2012) a Zona Norte da cidade de Macapá pode ser considerada uma "zona dormitório". Toste (2016a) complementa a afirmação de deste autor, afirmando que as áreas ocupadas na Zona Norte de Macapá apresentam, principalmente, a função residencial, o que provocava o deslocamento de muitos moradores para outras regiões da cidade para realizar atividades de ensino ou trabalho. Além disso, 
segundo Silva (2017, p.438) o surgimento dos loteamentos privados, "representam um tipo de segregação socioespacial que tem na propriedade privada e na apropriação privada de espaços públicos e coletivos sua base fundamental", provocando alterações na forma e no conteúdo da segregação socioespacial da Zona Norte.

Observou-se que a segregação socioespacial da área é causada pela ausência de infraestrutura urbana de qualidade que não atende na totalidade dos bairros da Zona Norte de Macapá. Problemas que vão desde a precariedade de serviços urbanos básicos, que incluem abastecimento de energia elétrica e água, coleta de lixo, esgotamento sanitário e drenagem de águas pluviais, até a quantidade insuficiente de equipamentos urbanos (unidades escolares e de saúde), além de espaços públicos.

Como forma de solucionar os problemas de infraestrutura urbana o Plano Diretor de Macapá (PMM, 2004) estabeleceu a criação das Áreas de Interesse Social e das Subzonas Prioritárias para Implantação de Infraestrutura Urbana, as quais incluem áreas de bairros da Zona Norte. Estas medidas tiveram o objetivo de reconhecer e determinar as áreas prioritárias para a implementação de políticas habitacionais e infraestrutura urbana. Entretanto, tais medidas não foram completamente postas em prática.

Tostes (2016a) comenta que desde a criação dos primeiros bairros houve o aumento significativo de equipamentos urbanos, sobretudo concentrados nas proximidades das principais vias da Zona Norte, a Rodovia Tancredo Neves e nas vias que dão sua continuidade. Dentre os principais equipamentos urbanos, pode-se citar a Estação Rodoviária de Macapá, o Departamento Estadual de Trânsito, o Corpo de Bombeiro, o Sistema Integrado de Atendimento ao Cidadão, Instituto Federal do Amapá - IFAP, dentre outros. Porém, ainda não suprem a demanda necessária para a população.

Segundo o estudo elaborado por Palheta et. al. (2016, p.10) os espaços públicos, como praças, parques e áreas verdes são fundamentais para a realização de atividades de esporte, lazer e cultura. Para os autores a problemática dos espaços públicos na Zona Norte de Macapá ocorre "porque não há de maneira distribuída locais apropriados para essas atividades e ainda se tem uma circulação bastante comprometida na maior parte dessa região por conta da falta infraestrutura viária".

Além da ausência de equipamentos urbanos, o fato da Zona Norte da cidade de Macapá ser separada geograficamente pela Área de Preservação Permanente do Canal do Jandiá e ser acesso de entrada e saída para os demais municípios do estado, provocaram sérios problemas de mobilidade urbana no trecho que começa na Ponte Engenheiro Sérgio Arruda e passa pela Rodovia Tancredo Neves, principal via da Zona Norte.

Segundo Tostes (2016a) a princípio o acesso à Zona Norte de Macapá era realizado por uma ponte com manilhas, sendo via de mão-dupla, popularmente conhecida como Bueiro do Pacoval, até a inauguração da ponte Engenheiro Sérgio Arruda (figura 5), em 2003. Porém, apesar do grande investimento na ponte, nunca recebeu reparos ao longo de mais de dez anos, o que acarretou a deterioração das rampas de acesso à estrutura, causando constante preocupação a população que frequentemente transita pela ponte (PACHECO, 2016). 
Figura 5 - Vista lateral da Ponte Sérgio Arruda sob o Canal do Jandiá

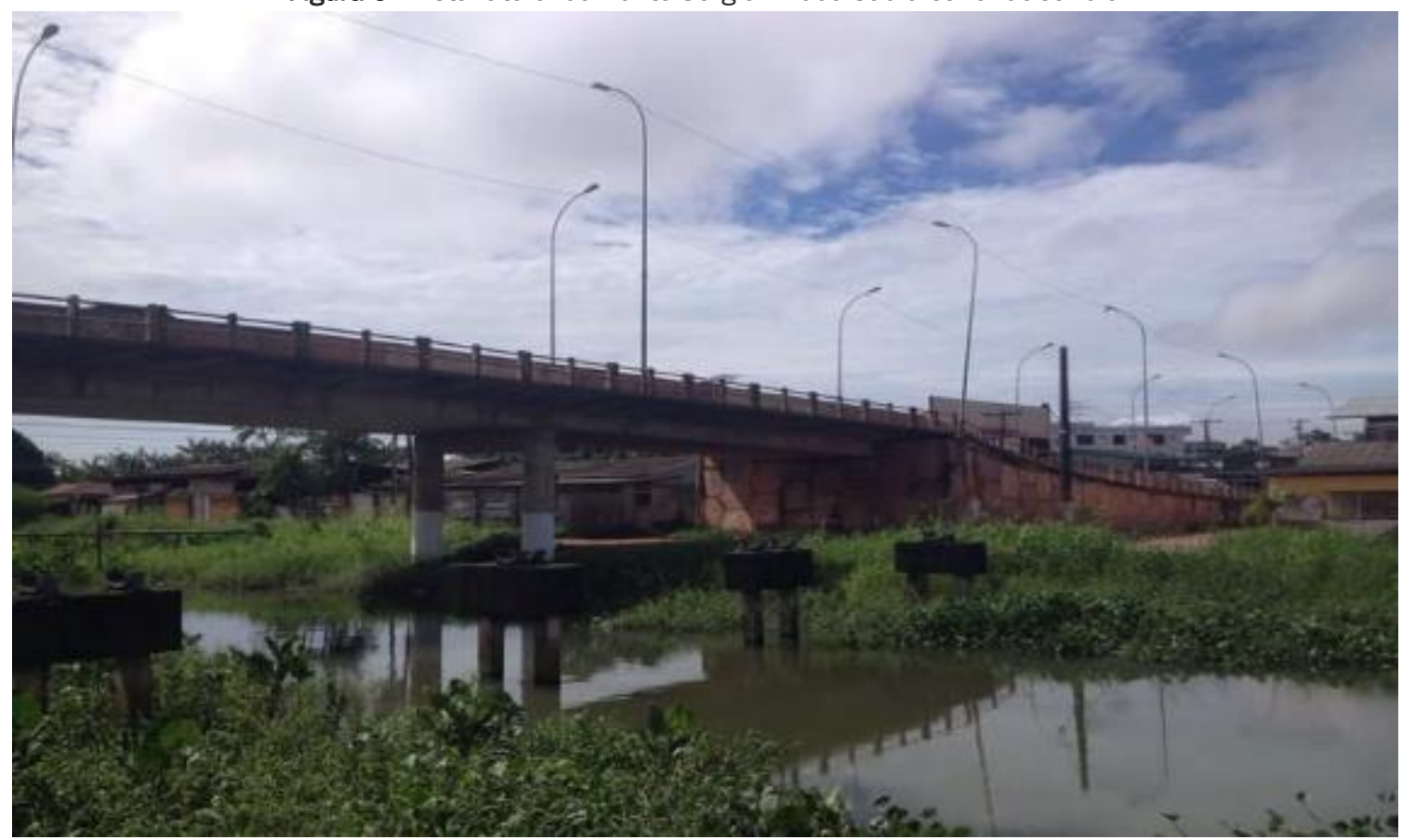

Fonte: Abinoan Santiago/G1. 2016.

Neste sentido, Tostes (2016a) afirma que o crescimento urbano da Zona Norte, acarretou a instalação de diferentes sinalizações de trânsito, como semáforos, redutores de velocidade e faixas para pedestres, em pontos estratégicos da Rodovia Tancredo Neves com o objetivo de diminuir os efeitos do intenso fluxo de trânsito. Porém, a partir da pesquisa de campo é perceptível a falta de infraestrutura para outras vias de rolamento menos importantes, que muitas vezes nem são asfaltadas e a qualidade precária ou inexistência de calçadas para os pedestres. Além disso, as vias priorizam os carros em detrimento de outros tipos de veículos, como ônibus e bicicletas.

É necessário, também, comentar sobre a degradação ambiental resultante da expansão urbana desordenada. O Plano Diretor de Macapá (PMM, 2004) descreve estes espaços, sejam ressacas ou canais urbanos que cortam a cidade, como bens a serem protegidos, regidos a partir de leis ambientais, no qual a população não poderia construir moradias. A mais evidente de todas era a ocupação irregular no Canal do Jandiá, cujos moradores foram remanejados em meados de 2018.

Segundo Cardoso (2012) a degradação ambiental pode ser causada tanto pela ocupação imprópria de aglomerados subnormais, como o uso indevido dos recursos naturais em loteamentos privados, próximos as áreas alagadas. Isso é reforçado por Rodrigues (2008) que aponta uma série de efeitos negativos causados pelos loteamentos privados, tais como: esgotos lançados nos cursos d'água, remoção de vegetação, privatização dos recursos naturais e contaminação das bacias pela ausência de infraestrutura básica.

\section{CONSIDERAÇÕES FINAIS}

O crescimento da Zona Norte de Macapá notadamente se deu tanto pela necessidade da cidade de se expandir horizontalmente, como pelo investimento dos setores público e privado em investir na região, sendo esta a zona que tem maior perspectiva de crescimento e investimento ao decorrer dos anos, principalmente por adquirir novos empreendimentos, fazendo com que se torne cada vez mais independente das 
demais Zona da cidade.

As consequências negativas que este crescimento trouxe faz com que seja necessário um maior investimento do setor público, não só em melhorar a mobilidade urbana do local com a execução da Rodovia Norte-Sul que pretende conectar a zona norte ao restante da cidade, mas também, a melhoria de outras infraestruturas, se não, esta região continuará a crescer de forma inadequada.

Portanto, é necessário a revisão de leis e códigos que regem a Zona Norte, por ser uma área de importante transição entre Macapá e outros municípios do Estado e por lidar futuramente com maiores impactos, principalmente com a possibilidade da criação da "Cidade Administrativa", onde os principais órgãos administrativos serão transferidos da zona central para a zona norte, que fará com que esta região seja cada vez mais valorizada.

Assim, a zona norte carece de maiores investimentos, e políticas públicas adequadas, que transforme a região e traga menos impactos sociais, ambientais e urbanos, em que a população residente tenha cada vez mais qualidade de vida, ao contrário o espaço ficará cada vez em uma situação insalubre, com uma segregação socioespacial cada vez maior.

\section{REFERÊNCIAS}

AMARAL, Marcio Douglas Brito; MELO, Alan Patrick Coimbra. Loteamentos Fechados em Cidades Médias da Amazônia: Um Estudo do Residencial San Marino (Macapá-AP). ACTA Geográfica, v.7, n.14, Boa Vista, jan./abr. de 2013. p.25-43

BEZERRA, Josué Alencar. Como definir o bairro? Uma breve revisão. Revista Geotemas, v. 1, n. 1, 2012. p. 21-31.

BRASIL, Lei n 6.766, de 19 de dezembro de 1979, Dispõe sobre o Parcelamento do Solo Urbano e dá outras Providências. Publicado no DOU de 20.12.1979.

Lei $n^{\circ}$ 4.591, de 16 de dezembro de 1964. Dispõe sôbre o condomínio em edificações e as incorporações imobiliárias. publicado no DOU de 21.12.1964 e retificado em 1.2.1965

CANTUÁRIA, Eliane Ramos. APA do Curiaú e a cidade: relações sociais, jurídicas e ambientais. Dissertação (Mestrado) Programa de Pós-Graduação em Direito Ambiental e Políticas Públicas.148 f. Universidade Federal do Amapá. Macapá: UNIFAP, 2011.

CARDOSO, Adauto Lucio. Assentamentos Precários No Brasil: Discutindo Conceitos. In: Caracterização E Tipologia De Assentamentos Precários: Estudos De Caso Brasileiros. Maria Da Piedade Morais, Cleandro Krause, Vicente Correia Lima Neto (org.). Brasília: Ipea, 2016.p. 29 - 52.

CARDOSO, Vanderlei Portela. Um Olhar Geográfico Sobre as Ocupações Irregulares na Cidade Brasileira. Monografia (TCC em Geografia). Universidade Regional do Noroeste do Rio Grande do Sul. ljuí: UNIJUI, 2012.

CARVALHO, G. M. de. Crescimento Urbano e Perda De Áreas Verdes em Macapá: Riscos E Possibilidades de Proteção. Monografia (TCC em Ciências Ambientais) Macapá: UNIFAP, 2013.

INSTITUTO BRASILEIRO DE GEOGRAFIA E ESTATÍSTICA - IBGE. Censo Demográfico, 2010a. Disponível em: <http://www.ibge.gov.br >. Acesso em: 12 maio 2019.

Aglomerados subnormais: Primeiros resultados. Rio de Janeiro, 2010b, p.19.

INSTITUTO DE MEIO AMBIENTE E ORDENAMENTO TERRITORIAL DO AMAPÁ - IMAP. Histórico de Loteamentos Urbanos. s.d. Disponível em: <http://www.imap.ap.gov.br/lista.php?cont=233\&a= 
220> Acesso em: 30 jan. 2017.

. Assentamentos Rurais e Urbanos. s.d. Disponível em: <http://www.imap.ap.gov.br/conteudo/gestao/assentamentos-rurais-e-urbanos> Acesso em: 15 maio 2019.

MARTINEZ, Gustavo Favaretto et. al. Habitação de Interesse Social: As Tipologias Habitacionais e o seu Reflexo na Produção da Cidade Através do Programa Minha Casa Minha Vida. Colloquium Humanarum, vol. 10, n. Especial 2, Presidente Prudente, jul./dez de 2013, p. 316-323.

MATSUTANE, Thiago Yugo Nagai et al. Loteamento de Interesse Social e a Expansão Urbana em Santo Anastácio-SP. Colloquium Socialis, Presidente Prudente, v. 01, n. Especial 2, jul/dez, 2017, p.794-800.

MARINHO, Izael. São Lazaro dribla o passado e cresce: com origens nas invasões próximas à antiga lixeira, o bairro tem privileigio de ser perto de tudo. 0 Liberal. 13 mar. 1997. Disponível: http://casteloroger.blogspot.com/2012/01/o-bairro-sao-lazaro-em-macapa.html. Acesso em 15 maio 2019.

PALHETA, A. Corina; et. al. Segregação ou Integração dos Espaços Públicos Urbanos: uma análise da Zona Norte de Macapá-AP. In: $7^{\circ}$ Congresso Luso Brasileiro para o Planejamento Urbano, Regional, Integrado e Sustentável-Contrastes, Contradições e Complexidades. Anais... 2016.p.1-12.

PACHECO, John. Rampas de acesso à ponte Sérgio Arruda, no AP, vão passar por reparos. G1 Amapá. 04 maio 2016. Disponível em: <http://g1.globo.com/ap/amapa/noticia/2016/05/rampas-de-acesso-ponte-sergio-arruda-no-ap-vao-passar-por-reparos.html>. Acesso em: 23 maio 2016.

PORTILHO, Ivone dos Santos et al. Políticas de desenvolvimento urbano em espaços segregados: uma análise do PDSA na cidade de Macapá (AP). Dissertação (Mestrado) Pós-Graduação em Geografia. 166f. Universidade Federal do Pará. Belém: UFPA, 2006.

PREFEITURA MUNICIPAL DE MACAPÁ - PMM. Lei Complementar n 026, Institui Plano Diretor de Desenvolvimento Urbano e Ambiental do Município de Macapá e dá Outras Providências. Macapá, jan. 2004.

RODRIGUES, S. Loteamentos Fechados e Condomínios Residenciais - Iniciativa Pública e Privada. In: VII Seminário Internacional da LARES Mercados emergentes de Real Estate: Novos Desafios e Oportunidades. São Paulo, 2008.

SILVA, Eliane Cabral da. A urbanização em Macapá após a criação do Estado do Amapá: expansão urbana e desigualdade socioespacial. Ciência Geográfica, v.21, Bauru, de jan.2017. p. 428-441.

TOSTES, José Alberto. A “explosão” da zona Norte da cidade de Macapá. 2016a Disponível em: <https://josealbertostes.blogspot.com.br/2016/09/a-explosao-da-zona-norte-da-cidade-de.html >. Acesso em: 30 jan. 2017.

, José Alberto. Planejamento urbano na cidade de Macapá: análise do projeto habitacional Macapaba. Atas de Saúde Ambiental (São Paulo, online), v. 4, jan. /dez. de 2016b, p. 1-21.

VIÉGAS, H. Zona Norte De Macapá. Disponível em: <http://realidadeurbanas.blogspot.com.br/ 2012/06/zona-norte-de-macapa.html>. Acesso: 22 maio 2019. 